\title{
Phenotypic and functional evaluations of peripheral blood monocytes from chronic-form paracoccidioidomycosis patients before and after treatment
}

\author{
James Venturini ${ }^{1,2^{*}}$, Ricardo Souza Cavalcante ${ }^{1}$, Márjorie de Assis Golim¹, Camila Martins Marchetti ${ }^{1,2}$, \\ Priscila Zacarias de Azevedo ${ }^{1}$, Bárbara Casella Amorim ${ }^{1,2}$, Maria Sueli Parreira de Arruda ${ }^{2}$ \\ and Rinaldo Poncio Mendes ${ }^{1}$
}

\begin{abstract}
Background: Paracoccidioidomycosis (PCM) is systemic mycosis caused by the thermal dimorphic fungus of genus Paracoccidioides, leading to either acute/subacute (AF) or chronic (CF) clinical forms. Numerous CF patients after treatment exhibit sequels, such as pulmonary and adrenal fibrosis. Monocytes are cells that are involved in the inflammatory response during active infection as well as in the fibrogenesis. These cells comprise a heterogeneous population with distinct phenotypic and functional activities. The scope of this study was to identify changes regarding functional and phenotypical aspects in monocytes comparing CF PCM patients on antifungal treatment versus non-treated patients (PMC-p).

Methods: Twenty-three CF PCM composed of 11 non-treated patients (NTG) and 12 patients in apparent cure (ACG) were studied. Sixteen healthy individuals were used as control group (CG). Monocyte subsets were determined by immunophenotyping based on CD14 and CD16 expression. Cellular function was measured in vitro with and without stimulation with lipopolysaccharide (LPS) and P. brasiliensis exoantigen (PbAg) for 24 hours. Independent samples were compared using unpaired $t$ tests, dependent samples were analyzed by paired t-test. Groups of more than two independent samples were analyzed using an ANOVA, with Tukey's post-test. Significance was set up at $p<0.05$.

Results: Our results showed high counts of peripheral blood $\mathrm{CD} 14^{+} \mathrm{CD} 16^{+}$and $\mathrm{CD} 14^{+} \mathrm{CD} 16^{++}$monocytes in untreated PCM-p accompanied by intense production of pro-inflammatory cytokines (IL-1 $\beta$ and TNF- $\alpha$ ) and profibrotic growth factors (TGF- $\beta 1$ and bFGF) by monocytes challenged with $P$. brasiliensis antigens. After the introduction of antifungal therapy, the counts of $\mathrm{CD} 14^{+} \mathrm{CD} 16^{+}$cells returned to baseline while $\mathrm{CD} 14^{+} \mathrm{CD} 16^{++}$ counts remained high. Interestingly, counts of $\mathrm{CD} 14^{+} \mathrm{CD} 16^{++}$monocytes remained elevated even $52 \pm 7$ months after successful antifungal treatment. Furthermore, the ACG-patients showed preserved pro-inflammatory activity in the presence of specific antigen stimuli and high spontaneous production of TNF-a by monocytes. (Continued on next page)
\end{abstract}

\footnotetext{
* Correspondence: james@fc.unesp.br

${ }^{1}$ Faculdade de Medicina de Botucatu, UNESP - Univ Estadual Paulista,

Botucatu, SP 18618-970, Brazil

${ }^{2}$ Faculdade de Ciências, UNESP - Univ Estadual Paulista, Bauru, Departamento

de Ciências Biológicas, Laboratório de Imunopatologia Experimental (LIPE),

Bauru, SP 17047-001, Brazil
} 
(Continued from previous page)

Conclusions: Infection with Paracoccidioides leads to initiation of a specific proinflammatory response by monocytes of PCM-p during active disease and in the apparent cure. A profibrotic profile by monocytes was observed only at admission. Furthermore, PCM-p with apparent cure showed high spontaneous production of TNF-a and high counts of CD $14^{+} \mathrm{CD} 16^{++}$monocytes, probably induced by hypoxia duo to fibrotic sequelae.

Keywords: Paracoccidioidomycosis, Monocyte subsets, Pulmonary fibrosis, Antifungal therapy

\section{Background}

Paracoccidioidomycosis (PCM) is a systemic and granulomatous mycosis caused by thermally dimorphic fungi of the Paracoccidioides brasiliensis complex and P. lutzii [1-3] and is characterized by antigen-dependent immunosuppression [4]. The active disease presents two main clinical forms: the acute/subacute form (AF) and the chronic form (CF). PCM patients (PCM-p) with the $\mathrm{AF}$ are typically young and normally show a short duration of the symptomatology (median of two months), exhibiting clinical manifestations that involve organs rich in the mononuclear phagocytic system (e.g. bone marrow, liver, spleen). CF usually affects adult males who present a long duration of the symptomatology ( $>6$ months) and exhibit predominant pulmonary and mucocutaneous involvement [5]. After treatment, numerous CF patients present sequelae, especially pulmonary fibrosis and emphysema, and Addison's syndrome [6].

As observed in other diseases caused by intracellular pathogens, the control of PCM depends on an effective and protective Paracoccidioides-specific host cellular immune response [7]. Although the adaptive immune response toward PCM is better characterized, immunity against the genus Paracoccidioides is complex and involves other immune cell subsets, including mononuclear phagocytes [7]. The immunophenotyping and functions under inflammatory and steady-state conditions of murine and human monocyte subsets have been investigated [8], and several studies have shown that monocyte subsets play different roles in the innate immune response during infectious processes and fibrogenesis $[9,10]$.

In humans, monocyte subsets can be identified by the expression of the surface molecules CD14 and CD16 [11]. CD $14^{+} \mathrm{CD} 16^{-}$monocytes are termed classical monocytes and represent approximately 90-95\% of human monocytes. These cells express high amounts of CCR1 and CCR2 and are characterized by moderate levels of the fractalkine receptor CX3CR1 and low HLA-DR. Furthermore, these cells exhibit intense phagocytic activity, produce high amounts of IL-10 upon lipopolysaccharide (LPS) stimulation and are the main precursors of tissue macrophages (reviewed in Zimmermann et al. [12]). Intermediate $\left(\mathrm{CD} 14^{+} \mathrm{CD} 16^{+}\right)$and non-classical or inflammatory $\left(\mathrm{CD} 14^{+} \mathrm{CD} 16^{++}\right)$subsets produce large amounts of proinflammatory mediators and are up-regulated in many inflammatory disorders, such as rheumatoid arthritis, atherosclerosis, bacterial sepsis and various hepatic diseases. Intermediate monocytes display high levels of HLA-DR, the mannose receptor and CCR5, and inflammatory monocytes exhibit high expression of CX3CR1 [12].

In PCM, the recovery of the immune response is a crucial step for considering successful the antifungal therapy. However, few reports have addressed immunological studies during the follow-up of PCM-p. Because interference with monocyte subset distribution and activation may be involved in PCM, we evaluated the phenotypic and functional aspects of the monocytes in non-treated CF PCM-p, as well as in patients that with apparent cure.

\section{Methods \\ Patients}

Twenty-three CF PCM patients (PCM-p) from the Tropical Diseases Ward and Outpatient Clinic for Paracoccidioidomycosis at the University Hospital, Faculdade de Medicina de Botucatu (FMB), UNESP-Univ. Estadual Paulista, Botucatu, SP, Brazil, were studied. Cases with clinical manifestations that were compatible with PCM were considered either confirmed or probable [13]. Cases were considered confirmed when the typical Paracoccidioides genus yeast forms were identified in the clinical specimens and probable when only serumspecific antibodies were detected using a double agar gel immunodiffusion test (DID). All patients exhibited pulmonary involvement and were classified as having clinical CF. Patients who exhibited neoplasia, inflammation, infectious diseases or pregnancy were not enrolled.

\section{Ethics statement}

This study was approved by the Research Ethics Committee of FMB-UNESP (\#3145/2009). Written informed consent to participate and to publish the data was obtained from all participants. In this study IRB was signed by all the adult patients. We had no IRB signed by the closest relative or the legal representative.

\section{Experimental design}

PCM-p were categorized into two groups: the nontreated group (NTG), consisting of 11 newly diagnosed 
patients, and the apparent cure group (ACG), consisting of 12 PCM-p who did not show any signs or symptoms and had a normal erythrocyte sedimentation rate (ESR), negative serology, and at least 2 full years of nontreatment after complete antifungal therapy [6]. The homogeneity of the groups was determined based on sex, age (years), clinical form and degree of severity, specific antibody serum levels and information on antifungal treatment (Table 1). Sixteen age- and sex-matched healthy individuals were selected among blood donors from the same geographical area to form the CG.

\section{Determination of the peripheral blood monocyte subsets}

Venous blood was collected in Vacutainer tubes (BD, Becton Dickinson, Franklin Lakes, NJ, USA) containing EDTA anticoagulant. Whole blood $(100 \mu \mathrm{l})$ was added into polystyrene tubes containing the following monoclonal antibodies: phycoerythrin (PE)-conjugated mouse IgG1 anti-human CD14, clone HCD14; peridinin chlorophyll protein complex (PerCP)-conjugated mouse IgG1 antihuman CD16, clone 3G8; and allophycocyanin (APC)-conjugated mouse IgG1 anti-human CD45, clone HI30, all of which were purchased from BioLegend (San Diego, CA, USA). The tubes were incubated for $20 \mathrm{~min}$ at $4^{\circ} \mathrm{C}$ and again after FACS lysing solution was added. The cells were washed with BD Pharmingen ${ }^{\mathrm{Tw}}$ stain buffer and analyzed using a FACSCalibur (BD). The data were analyzed using the FlowJo software (Tree Star Inc, USA). The cell counts were calculated based on peripheral leucocyte count (WBC).

\section{Monocyte culture}

Twenty milliliters of venous blood were collected in Vacutainer tubes (BD) containing heparin anticoagulant. Mononuclear cells were separated using a FicollHypaque (Sigma, St Louis, MO, USA) density gradient and suspended in $1.0 \mathrm{ml}$ of RPMI-1640 medium containing L-glutamine and $25 \mathrm{mM}$ HEPES buffer (Gibco,

Table 1 Clinical characterization of the patients

\begin{tabular}{|c|c|c|c|c|c|c|c|c|}
\hline Patients & Sex & Age $^{*}$ & Degree of severity ${ }^{*}$ & DID (1: ) - Admission* & Group & Antifungal & $\begin{array}{l}\begin{array}{l}\text { Length of treatment } \\
\text { (months) }\end{array} \\
\end{array}$ & $\begin{array}{l}\text { Length after treatment } \\
\text { (months) }\end{array}$ \\
\hline P1 & M & 60 & Moderate & 16 & NTG & - & - & - \\
\hline P2 & M & 53 & Severe & 128 & NTG & - & - & - \\
\hline P3 & M & 59 & Moderate & 32 & NTG & - & - & - \\
\hline P4 & $\mathrm{F}$ & 47 & Moderate & 64 & NTG & - & - & - \\
\hline P5 & M & 44 & Moderate & 64 & NTG & - & - & - \\
\hline P6 & M & 51 & Mild & NR & NTG & - & - & - \\
\hline P7 & M & 64 & Moderate & 32 & NTG & - & - & - \\
\hline P8 & M & 59 & Moderate & 32 & NTG & - & - & - \\
\hline P9 & M & 52 & Moderate & 8 & NTG & - & - & - \\
\hline P10 & M & 47 & Moderate & 32 & NTG & - & - & - \\
\hline P11 & M & 37 & Moderate & 4 & NTG & - & - & - \\
\hline P12 & M & 56 & Moderate & 16 & ACG & CMX & 25 & 28 \\
\hline P13 & M & 39 & Severe & 64 & ACG & CMX & 173 & 37 \\
\hline P14 & M & 60 & Mild & 16 & ACG & CMX & 97 & 45 \\
\hline P15 & M & 56 & Moderate & 16 & ACG & CMX & 26 & 3 \\
\hline P16 & M & 50 & Moderate & 512 & ACG & CMX & 53 & 62 \\
\hline P17 & M & 42 & Moderate & 8 & ACG & CMX & 28 & 83 \\
\hline P18 & M & 42 & Moderate & NR & ACG & ITC & 31 & 69 \\
\hline P19 & M & 39 & Moderate & 2 & ACG & ITC & 32 & 27 \\
\hline P20 & M & 40 & Severe & 128 & $A C G$ & CMX/ITC & $33^{(\mathrm{CMX})} / 49^{(\mathrm{ITC})}$ & 89 \\
\hline P21 & M & 42 & Severe & 64 & ACG & CMX/ITC & $6^{(\mathrm{CMX})} / 131^{(\mathrm{ITC})}$ & 53 \\
\hline P22 & M & 51 & Severe & 128 & ACG & CMX/ITC & $44^{(\mathrm{CMX})} / 12^{(\mathrm{ITC})}$ & 60 \\
\hline P23 & M & 53 & Severe & 64 & ACG & CMX & 84 & 65 \\
\hline
\end{tabular}

$\mathrm{DID}=$ double agar gel immunodiffusion test; $\mathrm{NR}=$ non-reagent; NTG = non-treated group; $\mathrm{ACG}=$ apparent cure group; $\mathrm{CMX}=$ cotrimoxazole; ITC = Itraconazole. *Homogeneity (NTG x ACG):

Age: NTG $=52$ (37-64); ACG = 46 (39-60); $p=0.18$ (Mann-Whitney U test).

Degree of severity: NTG $=$ ACG; $p=0.31$ (Fisher's exact test).

DID admission: NTG =32 (NR-1:128); ACG =32 (NR-1:512); $p=0.66$ (Mann-Whitney U test).

**Length of treatment (Mean \pm SEM): $68 \pm 14$; Length after treatment (Mean \pm SEM): $52 \pm 7$. 
Grand Island, NY, USA) supplemented with 10\% fetal calf serum (Gibco), penicillin (100 UI/ml) and streptomycin $(100 \mu \mathrm{g} / \mathrm{ml})$ (Gibco). The cell concentration was adjusted to $2.0 \times 10^{6}$ mononuclear phagocytes $\mathrm{ml}^{-1}$, as judged by the uptake of $0.02 \%$ neutral red. The mononuclear cells were placed in 96-well, flat-bottomed microtiter plates (Costar, Cambridge, MA, USA) and incubated for 2 hours at $37^{\circ} \mathrm{C}$ and $5 \% \mathrm{CO}_{2}$ in a humidified chamber to allow the monocytes to adhere and spread. Nonadherent cells were removed by washing the wells 3 times with RPMI-1640 medium, and the remaining adherent cells ( $>90 \%$ mononuclear phagocytes as assessed by the CD14 cell-surface expression) were used for experiments. The adherent monocytes were cultured at $37^{\circ} \mathrm{C}$ and $5 \% \mathrm{CO}_{2}$ in supplemented RPMI-1640 in the presence of medium only or optimal concentrations of LPS (10 $\mu \mathrm{g} \mathrm{ml} \mathrm{m}^{-1}$, Sigma) and $P$. brasiliensis exoantigen (20 $\mu \mathrm{g} \mathrm{ml}^{-1}$, Pb113 strain). After 24 hours, the cell-free supernatants were harvested and stored at $-80^{\circ} \mathrm{C}$ pending cytokine analysis.

\section{Quantification of cytokines}

The cytokines TGF- $\beta 1$, CCL3/MIP- $1 \alpha$, VEGF and bFGF were quantified using ELISA with the Cytokine Duo-Set Kit (R\&D Systems, Minneapolis, USA). IL-1 $\beta$, IL-6, IL10 , TNF- $\alpha$ and IL-12p70 were quantified using flow cytometry and the Human Inflammation Kit, $\mathrm{BD}^{\mathrm{tm}}$, Cytometric Bead Array (BD).

\section{Statistical analysis}

Statistical tests were performed using the GraphPad v.5.00 software (GraphPad Software Inc, San Diego, CA, USA), and significance was set up at $p \leq 0.05$ for all of the analyses. The homogeneity of the groups NTG and ACG was determined by Mann-Whitney $U$ test and Fisher's exact test. Comparisons of two independent samples were performed using unpaired $t$ test, two dependent samples using $t$-paired test, and comparison of more than two independent samples were performed using an ANOVA, with Tukey's post-test [14].

\section{Results}

Distribution of the blood peripheral monocyte subsets of PCM-p before antifungal treatment, during the antifungal treatment and after apparent cure

Although in both groups of PCM-p the total monocyte count $\left(\mathrm{CD} 45^{+} \mathrm{CD} 14^{+}\right)$was in the normal clinical range compared to healthy controls, the NTG group still showed significantly elevated $\mathrm{CD} 45^{+} \mathrm{CD} 14^{+}$cell counts (Figure 1C). In this group, we also observed high counts of $\mathrm{CD} 14^{+} \mathrm{CD} 16^{+}$and $\mathrm{CD} 14^{+} \mathrm{CD} 16^{++}$(Figure 1A, $B$ and $C)$. Five PCM-p from NTG were also evaluated after the introduction of antifungal therapy; we observed a significant decrease in $\mathrm{CD} 45^{+} \mathrm{CD} 14^{+}$cells and the counts of $\mathrm{CD} 14^{+} \mathrm{CD} 16^{++}$cells remained high (Table 2). PCM-p from ACG showed high counts of $\mathrm{CD} 14^{+} \mathrm{CD} 16^{++}$(Figure 1C).

\section{Production of inflammatory mediators/cytokines by monocytes from PCM-p before treatment and after apparent cure}

We determined the concentrations of IL-1 $\beta$, IL-6, TNF$\alpha$, IL-10, IL-12p70, CCL3/MIP-1 $\alpha$, TGF- $\beta 1$, FGF-b and VEGF in the supernatants of monocyte cell cultures in the presence or absence of LPS-nonspecific and P. brasiliensis antigen-specific stimuli. Among the mediators analyzed in the cell-free supernatant, VEGF and IL-12p70 had levels that were below the detection limits.

Independent of the stimuli, no differences in the production of IL-6, IL-10 and MIP- $1 \alpha$ were observed among the groups (Figure 2). The production of IL-1 $\beta$ and TNF$\alpha$ after specific-antigen challenge was higher in PCM-p regardless of treatment compared with the CG. Moreover, the spontaneous production of TNF- $\alpha$ was higher in both groups of patients than in the CG (Figure 2).

The specific-stimulus production of TGF- $\beta 1$ was higher in non-treated patients than normal subjects and similar to PCM-p with apparent cure (Figure 2). Similarly, the specific and non-specific stimulus production of bFGF was higher in non-treated patients than normal subjects and similar to PCM-p with apparent cure (Figure 2).

\section{Discussion}

Some aspects should be considered regarding the immunological evaluations of CF PCM-p. First, the CF is usually caused by reactivation of latent foci that were maintained for an unknown amount of time, potentially as long as 30 years [15]; thus, the host has previously organized an adaptive immune response against the genus Paracoccidioides that was efficacious for some time. Indeed, the prevalence of healthy subjects from endemic areas who have a positive intradermal skin test to paracoccidioidin and negative test for histoplasmin can reach $50 \%[16,17]$. Second, due to the long duration of symptomatology of $>6$ months, the clinical and immunological evaluations performed at admission occur in PCM-p who have responded to the paracoccidioidal antigens but without success because they show progression of the signs and symptoms [5]. In addition, the inflammatory response is intense but inefficacious [18-21]. Third, the lungs are the entry route for the fungus and one of the main target organs in the CF [22]. In this organ, peri-bronchial pulmonary lesions of the epithelioid granulomatous type are observed, followed by confluence and nodule formation, occasionally with central necrosis, which can drain its contents and form cavities [23,24]. 

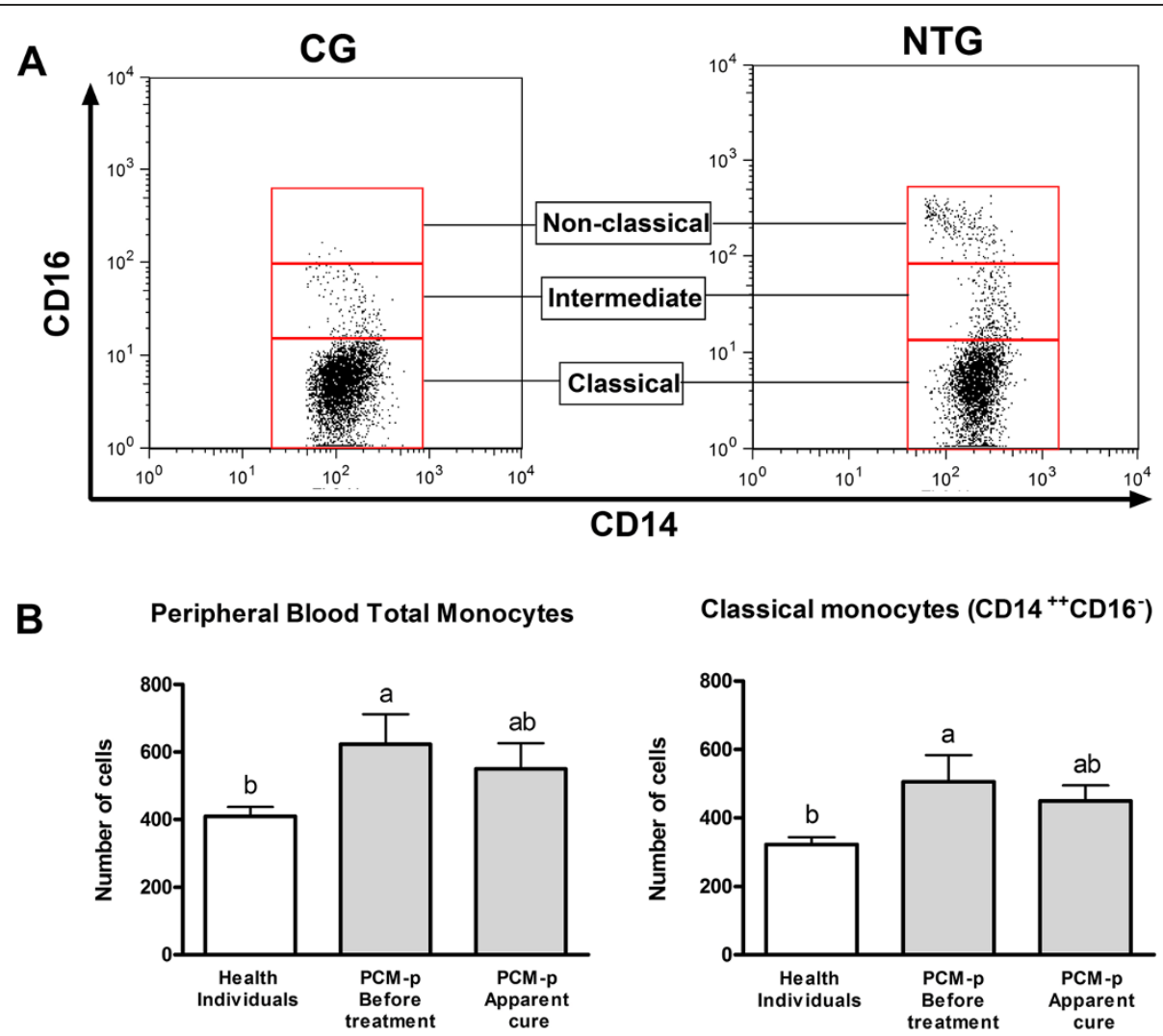

Classical monocytes (CD14 $\left.{ }^{++} \mathrm{CD}^{-} 6^{-}\right)$
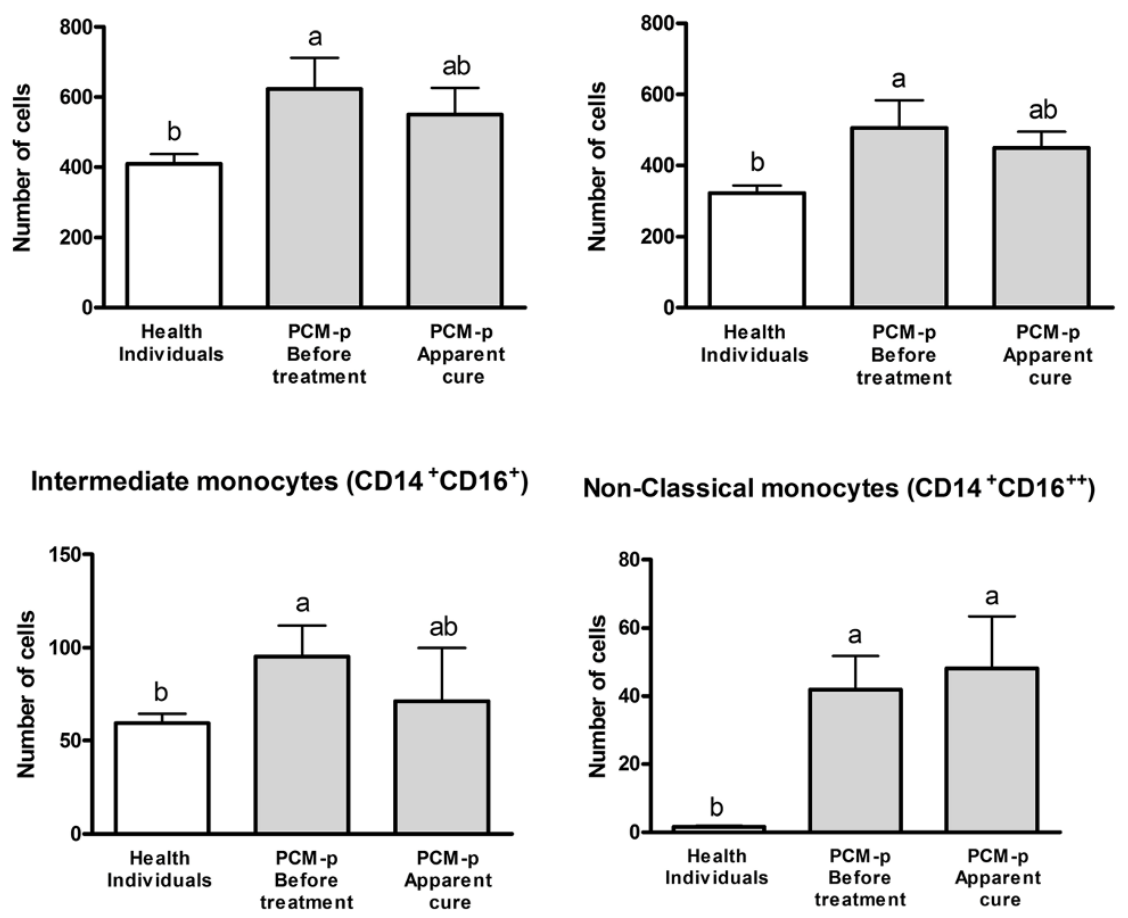

Non-Classical monocytes $\left(\mathrm{CD} 14^{+} \mathrm{CD} 16^{++}\right)$

Figure 1 Distribution of peripheral blood monocyte subsets. A. Dot plots showing the gate strategies used to identify the monocyte subsets

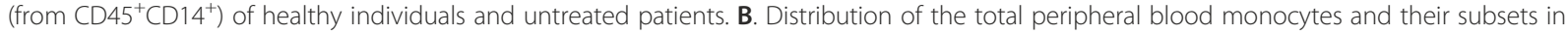
healthy individuals ( $C G, n=16)$, patients with PCM (PCM-p) before antifungal treatment ( $N T G, n=9)$ and PCM-p with apparent cure (ACG, $n=12)$. Values are expressed as the mean \pm standard deviation (cell counts of total peripheral leukocytes $-\mathrm{CD}_{4} 5^{+}$cells) and comparisons were performed by ANOVA with Tukey's post-test. Different letters indicate significant differences among the groups $(p \leq 0.05)$.

Furthermore, intense collagen I and III (reticulin fibers) deposition around the granuloma that interconnects neighboring structures, such as bronchi and blood vessels, occurs. In addition, reticulin proliferation is observed in the alveolar septae in non-granulomatous areas [25]. It is important to highlight that upon admission, CF patients typically present all of these pulmonary alterations, as identified by several biopsies and necroscopic studies $[24,26]$.
Here, we showed for the first time high counts of peripheral blood $\mathrm{CD} 14^{+} \mathrm{CD} 16^{+}$intermediate as well as $\mathrm{CD} 14^{+} \mathrm{CD} 16^{++}$non-classic monocytes in untreated PCM-p. Studies on infectious processes, such as Gramnegative bacteremia, have shown an increased number of monocytes $\mathrm{CD} 16^{+}$that normalizes after efficacious treatment [27]. In the present study, we observed that after the introduction of the antifungal therapy, the count of total monocytes and $\mathrm{CD} 14^{+} \mathrm{CD} 16+$ cells 
Table 2 Distribution of monocyte subsets of PCM-p during the follow-up

\begin{tabular}{|c|c|c|c|c|c|c|c|c|c|}
\hline \multirow[t]{2}{*}{ ID patient } & \multicolumn{4}{|c|}{ Before Treatment } & \multicolumn{5}{|c|}{ During the treatment } \\
\hline & $\mathrm{CD}^{+} 5^{+} \mathrm{CD} 14^{+}$ & $\mathrm{CD}_{14}^{+} \mathrm{CD} 16^{-}$ & $\mathrm{CD}_{14}{ }^{+} \mathrm{CD} 16^{+}$ & $\mathrm{CD} 14+\mathrm{CD} 16^{++}$ & $\overline{\mathrm{CD} 45^{+} \mathrm{CD} 14^{+}}$ & $\mathrm{CD}_{14}^{+} \mathrm{CD} 16^{-}$ & $\mathrm{CD}_{14}^{+} \mathrm{CD} 16^{+}$ & $\mathrm{CD}_{14}^{+} \mathrm{CD} 16^{++}$ & $\begin{array}{l}\text { Length of } \\
\text { treatment } \\
\text { (months) }\end{array}$ \\
\hline P3 & 348 & 327 & 16 & 5 & 331 & 307 & 6 & 18 & 17 (ITC) \\
\hline P6 & 933 & 716 & 158 & 58 & 221 & 430 & 16 & 18 & $20(\mathrm{CMX})$ \\
\hline P7 & 1164 & 959 & 118 & 88 & 776 & 610 & 4 & 23 & 20 (ITC) \\
\hline P8 & 457 & 346 & 82 & 30 & 214 & 290 & 6 & 10 & $20(\mathrm{CMX})$ \\
\hline P9 & 511 & 350 & 141 & 20 & 273 & 360 & 2 & 15 & 17 (ITC) \\
\hline $\begin{array}{l}\text { Mean } \pm \\
\text { SEM }\end{array}$ & $\begin{array}{l}682.6 \pm \\
156.0^{A}\end{array}$ & $\begin{array}{l}539.6 \pm \\
127.6\end{array}$ & $\begin{array}{l}103.0 \pm \\
25.2^{\mathrm{A}} \pm\end{array}$ & $\begin{array}{l}40.2 \pm \\
14.7\end{array}$ & $\begin{array}{l}363.0 \pm \\
105.4^{B}\end{array}$ & $\begin{array}{l}399.4 \pm \\
58.0\end{array}$ & $\begin{array}{l}6.8 \pm \\
2.4^{\mathrm{B}}\end{array}$ & $\begin{array}{l}16.8 \pm \\
2.1\end{array}$ & $18.8 \pm 1.4$ \\
\hline
\end{tabular}

Different letters indicate significant differences between the groups ( $p \leq 0.05$, $t$-paired test; A $>B$ ).

Values expressed as cell counts/ $\mu$ l.

decreased. All groups of PCM-p exhibited high counts of $\mathrm{CD} 14^{+} \mathrm{CD} 16^{++}$.

In addition to infectious processes, a recent report showed a higher frequency of intrahepatic intermediate monocytes in patients with chronic inflammatory and fibrotic liver diseases [28]. According to the authors, the intermediate subset can modulate liver fibrogenesis. Although we did not separately evaluate the functions of the monocyte subsets, the high percentage of $\mathrm{CD} 16^{+}$ monocytes in untreated CF PCM-p could be related to two typical morpho-functional aspects of these patients: an intense inflammatory response and pro-fibrotic activity. We observed high production of pro-inflammatory cytokines (IL1- $\beta$ and TNF- $\alpha$ ) and pro-fibrotic growth factors (TGF- $\beta 1$ and bFGF). This profile was similar to that observed in previous studies that evaluated several pro-inflammatory cytokines and TGF- $\beta 1[18,21]$. Considering that TGF- $\beta 1$ is a pleiotropic cytokine that exhibits a central role in fibrogenesis [29], as well as potent anti-inflammatory/regulatory activity [30], the bFGF dosage enhances early fibrogenesis in CF PCM-p.

In addition, we observed that some patients showed a normal distribution of monocyte subsets and/or levels of TGF- $\beta 1$ and bFGF. This finding could be associated with clinical observations of different degrees of fibrosis upon patient admission. Our group recently developed an algorithmic method to quantify pulmonary fibrosis and emphysema [31], and a study to correlate the different degrees of fibrosis and with the immune response is ongoing.

Herein, we also demonstrate for the first time that $P$. brasiliensis antigens significantly enhance the production of IL1- $\beta$, TNF- $\alpha$, TGF- $\beta 1$ and bFGF by peripheral blood monocytes of PCM-p, suggesting that fungal metabolites play an important role in the activation of these cells. Considering that monocytes are precursors for various tissue macrophages and dendritic cells and secrete several immune mediators in the pulmonary milieu during inflammation, it is possible that the recruitment of specific-stimulated monocytes into paracoccidioidal lesions could contribute to deleterious inflammatory tissue damage and trigger fibroblast and fibrocyte activation [32]. This hypothesis is supported by several studies that have demonstrated an array of strategies used by $P$. brasiliensis or its metabolites to manipulate host cells to survive and propagate (reviewed in Mendes-Giannini et al. [33]). Thus, we believe that our findings should open new perspectives for investigation, especially related to fibrosis in PCM-p.

We also investigated for the first time the functional aspects of the peripheral blood monocytes of PCM-p after treatment, i.e., with apparent cure. We found high levels of TNF- $\alpha$ and IL-1 $\beta$ in antigen-stimulated cell culture supernatants, which suggests preserved pro-inflammatory activity of the PCM-p monocytes when stimulated by paracoccidioidal antigens. In addition, we observed higher counts of $\mathrm{CD} 16^{++}$monocytes and high levels of spontaneous TNF- $\alpha$ release by monocytes from these patients. Considering that the pulmonary sequelae observed in CF PCM-p typically become worse after antifungal therapy is initiated $[6,34]$, it is possible that the higher levels of TNF- $\alpha$ are due to hypoxemia [35].

\section{Conclusions}

In summary, the present study showed that untreated PCM-p exhibit intense production of pro-inflammatory and pro-fibrotic mediators by monocytes challenged with $P$. brasiliensis antigens. They also exhibit high counts of $\mathrm{CD} 14^{+} \mathrm{CD} 16^{+}$and $\mathrm{CD} 14^{+} \mathrm{CD} 16^{++}$monocytes. After the introduction of antifungal therapy, the counts of $\mathrm{CD} 14^{+} \mathrm{CD} 16^{+}$returned to baseline. After complete treatment, monocytes from PCM-p showed preserved pro-inflammatory activity against specific stimuli, high spontaneous production of TNF- $\alpha$ and high counts of $\mathrm{CD} 14^{+} \mathrm{CD} 16^{++}$. Although the role of these cells is complex, we suggest that during the active disease, these 


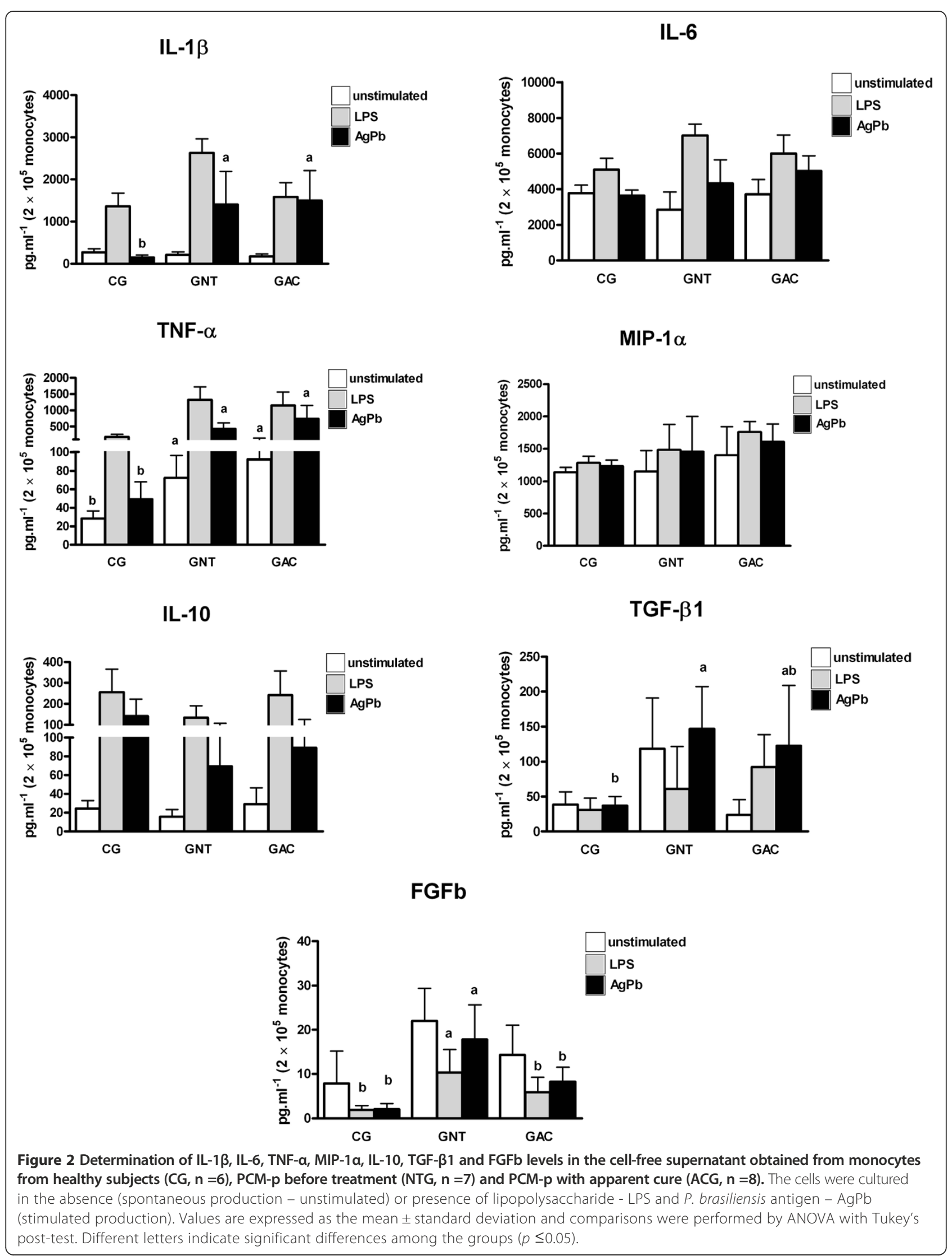


cells could act both in the proinflammatory response as wells as in the fribrogenesis; and after the treatment, the findings seems to be a consequence of hypoxemia due to pulmonary fibrosis.

\section{Abbreviations}

ACG: Apparent cure group; AF: Acute/subacute form; ANOVA: Analysis of variance; APC: Allophycocyanin; bFGF: Basic fibroblast growth factor; CCR: Chemokine receptors of the of the CC subfamily; CF: Chronic form; CG: Control group; CX3CR: Chemokine receptors of the of the CXC subfamily; DID: Double agar gel immunodiffusion test; EDTA: Ethylenediamine tetraacetic acid; ELISA: Enzyme-linked immuno sorbent assay; ESR: Erythrocyte sedimentation rate; FACS: Fluorescence-activated cell sorting; HEPES: Hydroxyethyl piperazineethanesulfonic acid; HLA: Human leukocyte antigen; IgG: Immunoglobulin G; IL: Interleukin; LPS: Lipopolysaccharide; MIP: Macrophage inflammatory protein; NTG: Non-treated group; PbAg: P. brasiliensis exoantigen; PCM: Paracoccidioidomycosis; PMC-p: Paracoccidioidomycosis patients; PE: Phycoerythrin; PerCP: Peridinin chlorophyll protein complex; TGF: Transforming growth factor; TNF: Tumor necrosis factor; VEGF: Endothelial growth factor.

\section{Competing interests}

The authors declare that they have no competing interests.

\section{Authors' contributions}

$J V$, MSPA and RPM conceived and designed the study; JV drafted the manuscript; RSC and RPM were responsible for patient recruitment and performed the clinical assessment; JV, CMM, BCA, PZA performed the culture cell and carried out the immunoassays; MAG. assisted with flow cytometry; JV, MAG, MSPA, RSC and RPM participated in the analysis and interpretation of data. All authors read and approved the final manuscript.

\section{Acknowledgments}

FAPESP provided financial support (09/51105-1 grant).The authors are grateful to Valéria Alves da Silva for providing helpful technical support with the flow cytometry assays and Dr Vânia Nieto Brito de Souza for her careful reading of the manuscript and the helpful comments.

Received: 17 March 2014 Accepted: 10 October 2014

Published online: 16 October 2014

\section{References}

1. Franco M, Peraçoli MT, Soares A, Montenegro R, Mendes RP, Meira DA: Host-parasite relationship in paracoccidioidomycosis. Curr Top Med Mycol 1993, 5:115-149

2. Matute DR, McEwen JG, Puccia R, Montes BA, San-Blas G, Bagagli E, Rauscher JT, Restrepo A, Morais F, Niño-Vega G, Taylor JW: Cryptic speciation and recombination in the fungus Paracoccidioides brasiliensis as revealed by gene genealogies. Mol Biol Evol 2006, 23:65-73.

3. Teixeira MM, Theodoro RC, de Carvalho MJ, Fernandes L, Paes HC, Hahn RC, Mendoza L, Bagagli E, San-Blas G, Felipe MS: Phylogenetic analysis reveals a high level of speciation in the Paracoccidioides genus. Mol Phylogenet Evol 2009, 52:273-283.

4. Benard G, Hong MA, Del Negro GM, Batista L, Shikanai-Yasuda MA, Duarte AJ: Antigen-specific immunosuppression in paracoccidioidomycosis. Am J Trop Med Hyg 1996, 54:7-12.

5. Mendes RP: The gamut of clinical manifestation. In Paracoccidioidomycosis. Edited by Franco MF, Lacaz CS, Retrepo A, Negro G. Boca Raton (FLA): CRC Press; 1994:233-258.

6. Mendes RP, Negroni R, Arechavala A: Treatment and control of cure. In Paracoccidioidomycosis. Edited by Franco MF, Lacaz CS, Retrepo A, Negro G. Boca Raton (FLA): CRC Press; 1994:373-392.

7. Benard G: An overview of the immunopathology of human paracoccidioidomycosis. Mycopathologia 2008, 165:209-221.

8. Tacke F, Randolph GJ: Migratory fate and differentiation of blood monocyte subsets. Immunobiology 2006, 211:609-618.

9. Serbina NV, Jia T, Hohl TM, Pamer EG: Monocyte-mediated defense against microbial pathogens. Annu Rev Immunol 2008, 26:421-452.

10. Kaufmann SH, Schaible UE: Antigen presentation and recognition in bacterial infections. Curr Opin Immunol 2005, 17:79-87.
11. Geissmann F, Auffray C, Palframan R, Wirrig C, Ciocca A, Campisi L, Narni-Mancinelli E, Lauvau G: Blood monocytes: distinct subsets, how they relate to dendritic cells, and their possible roles in the regulation of T-cell responses. Immunol Cell Biol 2008, 86:398-408.

12. Zimmermann HW, Trautwein C, Tacke F: Functional role of monocytes and macrophages for the inflammatory response in acute liver injury. Front Physiol 2012, 19:3-56.

13. Shikanai-Yasuda MA, Queiroz-Telles F, Mendes RP, Colombo AL, Moretti ML: Guidelines in paracoccidioidomycosis. Rev Soc Bras Med Trop 2006, 39:297-310

14. Zar JH: Biostatistical Analysis. New Jersey: Prentice Hall; 2010.

15. Balabanov K, Angelov N, Balabanoff V: South american (Brazilian) blasomycosis, description of the 1st case in Bulgaria. Surr Med 1965, 16:23-27.

16. Rodrigues CC: Avaliação da infecção por Histoplasma capsulatum por meio de reações intradérmicas em moradores da zona urbana e rural do Município de Pratânia (SP). In PhD Thesis. Botucatu, SP. Brazil: UNESP - Univ Estadual Paulista, Tropical Disease Area; 2004.

17. Marques AP, Oliveira SM, Rezende GR, Melo DA, Fernandes-Fitts SM, Pontes ER, Bonecini-Almeida Mda G, Camargo ZP, Paniago AM: Evaluation of Paracoccidioides brasiliensis Infection by gp 43 Intradermal Test in Rural Settlements in Central-West Brazil. Mycopathologia 2013, 176:41-47.

18. Peraçoli MT, Kurokawa CS, Calvi SA, Mendes RP, Pereira PC, Marques SA, Soares AM: Production of pro- and anti-inflammatory cytokines by monocytes from patients with paracoccidioidomycosis. Microbes Infect 2003, 5:413-448.

19. Calvi SA, Soares AM, Peraçoli MT, Franco M, Ruiz RL Jr, Marcondes-Machado J, Fecchio D, Mattos MC, Mendes RP: Study of bronchoalveolar lavage fluid in paracoccidioidomycosis: cytopathology and alveolar macrophage function in response to gamma interferon; comparison with blood monocytes. Microbes Infect 2003, 5:1373-1379.

20. Fornazim MC, Balthazar A, Quagliato R Jr, Mamoni RL, Garcia C, Blotta MH: Evaluation of bronchoalveolar cells in pulmonary paracoccidioidomycosis. Eur Respir J 2003, 22:895-899.

21. Parise-Fortes MR, Marques SA, Soares AM, Kurokawa CS, Marques ME, Peracoli MT: Cytokines released from blood monocytes and expressed in mucocutaneous lesions of patients with paracoccidioidomycosis evaluated before and during trimethoprim-sulfamethoxazole treatment. Br J Dermatol 2006, 154:643-650.

22. Queiroz-Telles F, Escuissato DL: Pulmonary paracoccidioidomycosis. Semin Respir Crit Care Med 2011, 32:764-774.

23. Brass K: Observaciones sobre la anatomia oatológica, patogenesis y evolución de La paracoccidiodomicosis. Mycopathol Mycol Appl 1969, 37:119-138.

24. Salfelder K, Doehnert G, Doehnert H-R: Paracoccidioidomycosis. Anatomic study with complete autopsies. Virchows Arch Abt A Path Anat 1969, 348:51-76.

25. Tuder RM, el Ibrahim R, Godoy CE, De Brito T: Pathology of the human pulmonary paracoccidioidomycosis. Mycopathologia 1985, 92:179-188.

26. Araujo SA: Contribuição ao estudo anátomo-clínico da paracoccidioidomicose em Minas Gerais. Meio século de experiência Avaliação das necropsias realizada no período compreendido entre 1944 até 1999, no Departamento de Anatomia Patológica e Medicina Legal, da Faculdade de Medicina da Universidade Federal de Minas Gerais. In Master Dissertation. Belo Horizonte, MG, Brazil: Universidade Federal de Minas Gerais; 2011.

27. Horelt A, Belge KU, Steppich B, Prinz J, Ziegler-Heitbrock L: The CD14 + CD16+ monocytes in erysipelas are expanded and show reduced cytokine production. Eur J Immunol 2002, 32:1319-1327.

28. Liaskou E, Zimmermann HW, Li KK, Oo YH, Suresh S, Stamataki Z, Qureshi O, Lalor PF, Shaw J, Syn WK, Curbishley SM, Adams DH: Monocyte subsets in human liver disease show distinct phenotypic and functional characteristics. Hepatology 2013, 57:385-398.

29. Fernandez IE, Eickelberg O: The impact of TGF- $\beta$ on lung fibrosis: from targeting to biomarkers. Proc Am Thorac Soc 2012, 9:111-116.

30. Li MO, Flavell RA: Contextual regulation of inflammation: a duet by transforming growth factor-beta and interleukin-10. Immunity 2008, 28:468-476.

31. Oliveira M, Pina DR, Alvarez M, Velo AF, Cavalcante RS, Yamashita S, Mendes RP, Miranda JR: Use of Algorithms for Semi-Automatic Quantification of Pulmonary Fibrosis and Emphysema. IFMBE Proceedings 2013, 39:819-822. 
32. Heymann F, Trautwein C, Tacke F: Monocytes and macrophages as cellular targets in liver fibrosis. Inflamm Allergy Drug Targets 2009, 8:307-318.

33. Mendes-Giannini MJ, da Silva JL M, de Fátima da Silva J, Donofrio FC, Miranda ET, Andreotti PF, Soares CP: Interactions of Paracoccidioides brasiliensis with host cells: recent advances. Mycopathologia 2008, 165:237-248.

34. Costa AN, Benard G, Albuquerque AL, Fujita CL, Magri AS, Salge JM, Shikanai-Yasuda MA, Carvalho CR: The lung in paracoccidioidomycosis: new insights into old problems. Clinics 2013, 68:441-448.

35. Tamaki S, Yamauchi M, Fukuoka A, Makinodan K, Koyama N, Tomoda K, Yoshikawa M, Kimura H: Production of inflammatory mediators by monocytes in patients with obstructive sleep apnea syndrome. Intern Med 2009, 48:1255-1262

doi:10.1186/s12879-014-0552-x

Cite this article as: Venturini et al:: Phenotypic and functional evaluations of peripheral blood monocytes from chronic-form paracoccidioidomycosis patients before and after treatment. BMC Infectious Diseases 2014 14:552.

\section{Submit your next manuscript to BioMed Central and take full advantage of:}

- Convenient online submission

- Thorough peer review

- No space constraints or color figure charges

- Immediate publication on acceptance

- Inclusion in PubMed, CAS, Scopus and Google Scholar

- Research which is freely available for redistribution 